\title{
Philosophical Theories, Aesthetic Value, and Theory Choice
}

\author{
Jiri Benovsky
}

Published online: 18 June 2013

(C) Springer Science+Business Media Dordrecht 2013

The practice of attributing aesthetic properties to scientific and philosophical theories is commonplace. Perhaps one of the most famous examples of such an aesthetic judgement about a theory is Quine's in 'On what there is': "Wyman's overpopulated universe is in many ways unlovely. It offends the aesthetic sense of us who have a taste for desert landscapes [...]". 1 Many other philosophers and scientists, before and after Quine, have attributed aesthetic properties to particular theories they are defending or rejecting. One often hears that a view is "elegant", "attractive", "beautiful", or even "sexy". The physicist Brian Greene decided to call the book, where he explains and defends the theory of superstrings for a general readership, "The elegant universe". And Dirac commented on general relativity theory thus: "The foundations of the theory are, I believe, stronger than what one could get simply from the support of experimental evidence. The real foundations come from the great beauty of the theory. [...] It is the essential beauty of the theory which I feel is the real reason for believing in it". ${ }^{2}$ When defending fourdimensionalism, Ted Sider could not be more explicit: "It is easy to feel [...] an intellectual joy in contemplating a theory so elegant and beautiful as fourdimensionalism, and it is tempting to accept the theory simply on this basis, utilizing arguments to rationalize more than justify". ${ }^{3}$ The list could go on and on.

\footnotetext{
1 Quine, W. V. 1948. On What There Is. Review of Metaphysics 2: 21-38.

2 Dirac, P. A. M. 1980. The Excellence of Einstein's Theory of Gravitation. In Goldsmith, Mackay, and Woundhuysen, eds., Einstein: The First Hundred Years. Oxford: Pergamon Press, p.10.

3 Sider, T. 2001. Four-dimensionalism. Clarendon Press, p. 74.

J. Benovsky $(\bowtie)$

Department of Philosophy, University of Fribourg, Av. de l'Europe 20, 1700 Fribourg, Switzerland e-mail: jiri@benovsky.com

URL: www.jiribenovsky.org
} 
The general claim that aesthetic properties supervene on non-aesthetic properties is a largely debated one. ${ }^{4}$ In this paper, I wish to address this issue from an angle which has not been really explored so far: I shall neither concentrate on cases of artefacts nor of natural objects, like the beauty of a painting or the beauty of a sunrise, rather, my main centre of attention will be the somewhat more special, theoretical case of the beauty of philosophical theories (with a focus on metaphysical theories). As we will see, there are some interesting issues concerning claims that attribute aesthetic properties to theories, in part because, even if such claims are commonplace in philosophy and in science, little has been said about the nature of the relevant supervenience basis - that is, about what it is exactly that the beauty of a theory is supposed to supervene $o$.

Moreover, we shall see that aesthetic properties of theories play a crucial role in theory choice and evaluation. Indeed, Sider's and Dirac's quotes above already anticipate explicitly a point I will discuss in detail below: it seems that the aesthetic properties of a theory can be appealed to when it comes to preferring one theory over another.

But before we ask ourselves what role the attribution of aesthetic properties to theories can play, let us see how theories come to have their aesthetic properties, in the first place.

\section{Aesthetic Grounding}

The general claim I will consider here is: the having of aesthetic properties by theories is grounded in their having other non-aesthetic properties. In a different article, ${ }^{5}$ I explore in detail the general claim of 'aesthetic supervenience' affecting any kind of object - e.g., artworks or natural objects such as a sunrise - and I argue that instead of appealing to a relation of supervenience, we should rather use a richer, asymmetric, and irreflexive, relation, and I defend the claim that the relation of grounding does a much better job than supervenience. 'Aesthetic grounding' is thus what we want, instead of aesthetic supervenience. In this article, I will set aside this dispute, and focus my interest on the issue concerning what kind of 'basis', that is, what kind of non-aesthetic properties, the aesthetic properties of theories are grounded in.

\footnotetext{
${ }^{4}$ See, for instance, Sibley, F. 1959. Aesthetic Concepts. Philosophical Review 68: 421-450; Levinson, J. 1984. Aesthetic Supervenience. Southern Journal of Philosophy 22, Supplement (1984): 93-110; Pettit, P. 1987. The Possibility of Aesthetic Realism. In Schaper (ed.), Pleasure, Preference and Value. Cambridge University Press; Mackinnon, J. E. 2001. Aesthetic Supervenience : For and Against. British Journal of Aesthetics, vol. 41, no. 1; Zangwill, N. 1994. Supervenience Unthwarted: Rejoinder to Wicks, Journal of Aesthetics and Art Criticism, vol. 52; Zangwill, N. 2001. The Metaphysics of Beauty. Cornell University Press; Zangwill, N. 2003. Beauty. In Jerrold Levinson (ed.), Oxford Companion to Aesthetics. Oxford University Press. My own discussion of this issue is to be found in Benovsky, J. 2012. Aesthetic Supervenience vs. Aesthetic Grounding. Estetika: The Central European Journal of Aesthetics XLIX/V, $\mathrm{n}^{\circ} 2,166-178$.

5 Benovsky, J. 2012. Aesthetic Supervenience vs. Aesthetic Grounding. Estetika: The Central European Journal of Aesthetics XLIX/V, n², 166-178.
} 
Theories are objects of a special kind that possess various (meta-)theoretical virtues, and these non-aesthetic evaluative properties of theories constitute the first (and central) part of the basis in which aesthetic properties of theories are grounded. Among these non-aesthetic evaluative properties, we find quite trivial ones like internal consistency, which every theory needs to posses anyway in order to qualify as an acceptable theory in the first place, as well as a number of other, more controversial ones, such as, explanatory power, simplicity, parsimony, preservation of and compatibility with intuitions, compatibility and fruitful interaction with other (philosophical and/or scientific) theories, and also the somewhat peculiar property theories are sometimes argued to have which consists in the theory's being the only one that works (I have in mind here argumentative strategies, such as, in "On the plurality of worlds" where a very significant part of David Lewis' argument for his favourite theory consists in showing that any alternatives fail).

I shall return to the role of these features of theories below. Before I do so, however, let us focus on two other crucial ingredients that enter into the mix of a theory's aesthetic properties, namely, first, the history and context of production and, second, the informed and well-developed taste of the evaluator.

\section{The Context of Origin}

Indeed, just as it is often argued in the case of artworks, the basis in which aesthetic properties of theories are grounded should include the context within which a given theory was formed. Exactly as the aesthetic value of a painting or a novel is influenced by its creative origins (the historic, social, political, etc. contexts determining the artwork's originality or even meaning (for instance, in the case of a novel such as Orwell's “1984”)), the respective historical period and the context of the creation of a philosophical theory will matter for the attribution of aesthetic properties.

More precisely, in addition to colours and shapes, etc. - but note that different types of objects, like symphonies, would possess other first-order non-aesthetic properties - some relational properties also have to be included in the basis in which aesthetic properties of artworks are grounded. These include, typically, the history and context of production of an artwork (see, for instance, Levinson ${ }^{6}$ ). In Walton's terms, ${ }^{7}$ aesthetic properties of an object depend not only on its narrow non-aesthetic properties, but also, importantly, on broad non-aesthetic relational properties, like the process and history of production of an artwork as well as the context in which it was created. Two indistinguishable paintings, indiscernible in the sense that they are exact duplicates and exactly the same arrangements of paint on a canvas of the same size, shape, texture, and so on, would (or, at least, could) still possess different aesthetic properties depending, for instance, on the period when they were created.

\footnotetext{
${ }^{6}$ Levinson, J. 1984. Aesthetic Supervenience. Southern Journal of Philosophy 22, Supplement (1984): 93-110, pp. 93-94.

7 Walton, K. 1970. Categories of Art. Philosophical Review, vol. 79
} 
This 'broadening' of the grounding basis solves a problem raised by Scruton, ${ }^{8}$ who criticizes the aesthetic supervenience thesis when he says that "different emergent 'properties' can depend on precisely the same set of 'first order' properties". What he has in mind here is that one and the same artwork can be context-dependently characterised as sad or as joyful, without contradiction. (For a discussion of this phenomenon, see for instance Pettit, ${ }^{9}$ Zangwill, ${ }^{10}$ and MacKinnon ${ }^{11}$ ). We can now respond to such an objection simply by pointing out that, once we include the context of production (and the context of evaluation - see more on 'taste' below) in the grounding basis, it is not anymore the case that 'different emergent properties could arise from the same basis'.

When it comes to theories, the kind of relevant context I have in mind is in particular the state of philosophical and scientific knowledge at the time of the formation of the theory to be evaluated. Take the case of Thales' materialist conception of the world, based on the idea of water as the central element out of which all other existing material entities are somehow construed. Clearly, such a view, evaluated in the light of today's scientific and philosophical knowledge, is false and not very satisfactory with respect to several of the evaluative criteria listed above (explanatory power, compatibility with other successful theories, etc.). Does this mean that Thales' view cannot be said to be beautiful? No, for the reason mentioned above: the context of origin of this metaphysical theory is to be taken into account when evaluating the theory's beauty, exactly as in the case of works of art. This means that, when we say that aesthetic properties of theories are grounded in their non-aesthetic properties, the grounding basis has to be widened to include their context of origin as well as the other non-aesthetic features - and, from the point of view of scientific and philosophical knowledge in the 6th century B.C., Thales' theory represents quite an achievement, in terms of systematization and philosophical reflection.

But this approach seems to generate a result that, while welcome in the case of artworks, such as, paintings, is distinctly undesirable in the case of metaphysical theories: Thales' view (and, of course, many an ancient, medieval, and modern view) could very well emerge from the evaluative procedure as being judged just as beautiful as the best metaphysical theories we have today. This state of affairs is acceptable in the case of, say, paintings since there is no good reason for claiming that today's paintings are in any principled way superior to older ones, but it is an unacceptable result in the case of philosophical theories, because it does not do justice to the progress of philosophical knowledge. In short, we want to say that, even if it is not always the case, generally speaking, our theories become better more beautiful - over time (recall Sider's and Dirac's quotes; indeed, all this

\footnotetext{
${ }^{8}$ Scruton, R. 1974. Art and Imagination: A Study in the Philosophy of Mind. St. Augustine's Press, p. 36.

9 Pettit, P. 1987. The Possibility of Aesthetic Realism. In Schaper (ed.), Pleasure, Preference and Value. Cambridge University Press.

${ }^{10}$ Zangwill, N. 1994. Supervenience Unthwarted: Rejoinder to Wicks, Journal of Aesthetics and Art Criticism, vol. 52 .

11 Mackinnon, J. E. 2001. Aesthetic Supervenience: For and Against, British Journal of Aesthetics, vol. 41, no. 1 .
} 
becomes crucially important if one takes the beauty of a theory to drive one's choice in deciding which particular theory is supposed to be the best). But it seems that, if aesthetic properties are grounded not only in their intrinsic non-aesthetic features but in a wider basis that includes the context of origin, it could perhaps even be possible to judge Thales' view as better (because more beautiful) than some of the most elaborate theories we have today.

However, the impasse here is only apparent. For, unlike paintings or other art forms, metaphysics exhibits one important feature which it shares with all the other sciences and philosophical disciplines: its knowledge accumulates over time. Another way of bringing out this point is to say that the contemporary context of origin of metaphysical theories does in a certain sense include all past contexts, since it includes all the successful discoveries of the past. This is why the contemporary context is to be privileged over any other past contexts, and, consequently, contemporary metaphysical theories can be said to be better than past ones (if they are beautiful enough) and claims about the progress of knowledge in philosophy can be secured.

Nevertheless, the general idea I wish to propose here still $i$ s analogous to the case of artworks like paintings. Its core claim is simply this: since the context of origin is part of the basis in which aesthetic properties of theories are grounded, the context of contemporary theories is richer than the context of 'older' theories. Suppose I see a painting in the museum which I intuitively like and find beautiful without however knowing anything about its context of creation. Suppose further that a museum guide comes along and provides me with interesting background information about the relevant context, for instance, that the painting was created in the Czech Republic in the eighties and that it has a particular political significance as a metaphorically veiled rejection of the communist regime at the time. After I have been given this information, I might find the painting even more beautiful than before. Suppose the guide goes on to tell me about the painter's life and reveals to me even more about the context of the painting's creation, for instance, that the painting also offers a metaphorical reference to the day when the painter lost his child - I might again find the painting now even more beautiful. In short, what I want to express here is the general thought that, the richer the context, the (potentially) more beautiful the painting will be to the beholder. What is more, it seems to me that this applies even more clearly in the case of philosophical theories.

\section{The Taste of the Evaluator}

The taste of the evaluator and her capacity to recognize and assess aesthetic features of works of art has often been argued to be of the utmost importance in the attribution of aesthetic properties; indeed, it seems that it should be included in the basis in which the aesthetic properties of the artwork are grounded. Here, 'taste' does not simply stand for 'liking' but a more elaborate capacity of the evaluator (one that can be trained), as for instance Sibley" makes clear : "When I speak of

12 Sibley, F. 1959. Aesthetic Concepts. Philosophical Review 68: 421-450, p. 423. 
taste [...], I shall not be dealing with questions which center upon expressions like 'a matter of taste' (meaning, roughly, a matter of personal preference or liking). It is with an ability to notice or discern things that I am concerned."

The interesting difference between the case of artworks (paintings, novels, etc.), on the one hand, and the case of philosophical or scientific theories, on the other, is that the claim is much less controversial in the latter case than in the former. Consider Hume's assertion that not everybody's taste provides for a good enough judgement, that is, the claim that not everyone is a good art critic (see Hume's 'On the standard of taste ${ }^{13}$ ). When it comes to evaluating philosophical and scientific theories, such a statement amounts to something quite trivial: only trained and informed philosophers and scientists can claim to be good judges of the beauty of theories. Furthermore, following Hume, these qualified judges must obey additional constraints, such as, being practised in the attribution of aesthetic properties to theories, having a "good sense", and being intellectually honest (for instance, in avoiding both jealousy and sympathy towards the author when evaluating her theory)). While in the case of Hume's view, such a claim is of course controversial, since he was interested in aesthetic judgements about works of art where prima facie anybody feels that she 'has the right' to claim to be a good judge of what is beautiful and what is not (see Sibley ${ }^{12}$ for an interesting discussion), in the more limited case of evaluating philosophical and scientific theories, disqualifying untrained 'common sense' opinions only seems the natural thing to do - indeed, the beauty of theories is grounded at least partly in their non-aesthetic features and only if those features are known and well understood can one start to be a good judge of the overall beauty of the theory at hand.

Much less controversially than in the case of artworks like paintings, then, it seems true that (i) only the aesthetic judgements of trained, qualified, relevantly competent, and appropriately sensitive and receptive philosophers and scientists, who exercise their taste in a proper way, should count, and that (ii) these judgements should indeed be included in the basis in which a theory's aesthetic properties are grounded. In short, only a trained and perceptive philosopher or scientist will be able to notice and appreciate a theory's beauty, and her taste and judgement is crucially relevant to any attribution of aesthetic properties. (In $\S 7$, I shall say more about the role taste plays here.)

\section{Theory Choice}

We now start to have a better idea of the nature of the basis in which aesthetic properties of theories are grounded. We also already saw (recall the quotes from Dirac and Sider above, to which one could add many other examples from the history of philosophy and science) that many evaluative aesthetic judgements proffered by skilled practitioners of philosophy and science aim not only at the

\footnotetext{
13 Hume, D. 1985. Of the Standard of Taste. In Miller, ed., Essays: Moral, Political, and Literary. Indianapolis: LibertyClassics.
} 
attribution of aesthetic properties to theories for their own sake, but also aim at providing a basis for choosing one theory over another.

It seems to be a natural attitude amongst scientists and philosophers to be inspired by the beauty of a theory in defending it against its competitors. Beauty (or other aesthetic properties of theories, such as, elegance) thus seems to be an important meta-theoretical criterion when it comes to theory choice. If this were indeed so (I should add that I myself, as a philosopher involved in the building and evaluating of theories, feel very sympathetic to this meta-theoretical attitude), aesthetic values would render us a great service because, very importantly, none of the traditional evaluative non-aesthetic criteria can in fact assist us in selecting one theory over another. I argue for this last claim in detail elsewhere ${ }^{14}$ by discussing each of the following meta-theoretical criteria in turn: internal consistency, explanatory power, simplicity, parsimony, preservation of and compatibility with intuitions, compatibility and fruitful interaction with other (philosophical and/or scientific) theories, as well as some other. This is not the place to get involved in a meta-philosophical discussion concerning these evaluation criteria again, but we do need to get at least a partial understanding of the kind of reasons why they do not allow us to select one theory as being better than its competitors - only then can we appreciate what a service aesthetic values of theories can render us, and how. For our present purposes, I will thus consider briefly in the next two sections two illustrative examples of the criteria of simplicity and parsimony and preservation of and compatibility with intuitions, which are often taken to be central to our metatheoretical thinking and theory evaluation.

\section{Simplicity and Parsimony}

Indeed, when comparing and evaluating theories, their 'simplicity and parsimony' property counts among the most influential meta-theoretical criteria. One important difficulty with this criterion concerns the fact that several criteria can be distinguished here: simplicity of the structure of the theory, number and complexity of primitives in the theory, qualitative parsimony (which concerns the number of kinds of entities), quantitative parsimony (which concerns the number of entities). Thus, there is not one, but there are (at least) four evaluative criteria one can use in comparing theories. Furthermore, these four different criteria are related. For instance, with greater complexity of the structure of the theory, it is likely that a theory will be able to be more parsimonious with respect to the number and complexity of its primitives, and vice versa. Also, if a theory postulates more kinds of entities, it may then be more parsimonious with respect to the number of these entities; think, for instance, of the Theory of Universals, which postulates the existence of universals and particulars, as compared to Trope Theory, which postulates only particulars - tropes - but where for each instantiation of a universal there supposedly exists a different trope (i.e., there are as many entities as there are instantiations of a universal; we have then more entities, on the one hand, and fewer

\footnotetext{
${ }^{14}$ Benovsky, J. manuscript. Theory choice, primitiveness, and metaontology.
} 
entities but more kinds of entities, on the other). Thus, being more parsimonious with respect to some of the criteria above is very likely to force one to be less parsimonious with respect to others.

It then becomes a matter of great subtlety and intricacy to determine which one of the various kinds of simplicity and parsimony is the evaluative criterion one should appeal to in theory choice (where one can be expected to do so in a non-questionbegging way by trying to be as fair to one's opponent as one is to one's own theory). We therefore often end up in a situation where we all know and agree which theory is more parsimonious in relation (say) to its axioms and which one is more parsimonious with respect to its structural complexity. But this by itself does not yet enable us to make a choice, given that it is unclear which one of the states of affairs is better - that is, we are usually perfectly able to evaluate the competing theories and attribute to them the 'first-order' properties of being more or less simple and parsimonious with respect to such and such a precise criterion of simplicity and parsimony, but it is much harder to use these property attributions to ascribe 'second-order' value properties to the competing theories, that is, properties, such as, being better.

\section{Intuitions}

Similar, and other, difficulties arise in the case where one tries to appeal to intuitions in order to claim that one theory is better than its competitors. What does it mean for a theory to be intuitive or counter-intuitive, and how is it relevant ? RodriguezPereyra writes :

I cannot see why theories in general should preserve intuitions, that is, pretheoretical and uncritical beliefs. No doubt there are areas, like some areas of Philosophy of Language, where intuitions are of paramount importance. Do definite descriptions name things ? Are proper names rigid designators ? Is a 'simple' sentence like 'Superman went into the telephone booth' extensional? Intuitions are of great importance in answering these and similar questions having to do with meaning. The reason for the importance of intuitions in this area is that, after all, meaning is something we do and so we can reasonably expect that our intuitions about meaning will be approximately correct.

But with metaphysical theories about the basic structure of the world, like Resemblance Nominalism and other solutions to the Problem of Universals, there is no reason to expect that our pre-theoretical beliefs and opinions will be true. [...] [O]ne should always keep a critical eye upon intuitions and be ready to discard those that are not validated by a rational and critical assessment or those that conflict with scientific or philosophical theories. Merely preserving certain intuitions does not make a theory better. ${ }^{15}$

\footnotetext{
15 Rodriguez-Pereyra, G. 2002. Resemblance Nominalism, A Solution to the Problem of Universals. Oxford, p. 217.
} 
Rodriguez-Pereyra describes intuitions as being "pre-theoretical" and "uncritical" - he takes them to be opinions/beliefs of untrained common sense. I agree that with respect to this sort of intuitions, what he says is largely right. Such intuitions do sometimes count, but not in all areas of philosophy, and only to some extent. Metaphysics probably is among the areas of philosophy where intuitions count the least. Furthermore, even if such intuitions were to count, their role would not be trouble-free. They are not universally shared, and even variable over time for one thinker - consequently, it is hard to use them to establish any permanent and universal result. Also, it is notoriously difficult to distinguish between 'good' and 'bad' intuitions - we often have conflicting intuitions, or weaker and stronger intuitions, and it is far from clear how to sort them out as being more or less fundamental and/or reliable. Thus, relying on such intuitions when doing metaphysics is really relying on something rather unreliable.

But there is also another kind of intuitions, perhaps more serious: the intuitions of the philosopher who considers a certain thesis, proposition, concept, ... and looks for an intuitive understanding of it. Here, the idea is that mainly by considering particular cases, examples, or by making thought-experiments, one can make more precise and more salient some intuitions that are stronger than mere uncritical opinions of common sense, and that arise from careful consideration of the case or thought-experiment. For instance, imaginary cases or Star Trek stories of duplication of persons in the debate about personal identity allow us to give rise to some more carefully formulated and useful intuitions, that can probably do some helpful work in the understating of our concept of a person and its conditions of persistence through time.

But even there, similar worries as with respect to the first sort of intuitions apply. Firstly, as before, even these 'more serious' intuitions do not seem to be relevant in all areas of philosophy, like in the field of fundamental metaphysics (say, the debate between the Theory of Universals, Trope Theory, and Nominalism) that is just too abstract and theoretical for any useful intuitions to arise. Secondly, even intuitions of this more serious kind suffer from being too unsettled and variable from one thinker to another and over time for one and the same thinker, and even there conflicting intuitions, good and bad intuitions, as well as weak and strong intuitions can arise - thus, for similar reasons as before, they do not seem to be a very reliable guide, even if they are more reliable and at least to some extent more useful than the uncritical and pre-theoretical intuitions of the first kind.

Take the case of the debate between the Theory of Universals, Trope Theory, and Nominalism. Rodriguez-Pereyra, while defending his Resemblance Nominalism, thinks that his own view suffers from being less intuitive than its competitors (but he does not think that it is a strong drawback, following the considerations above). His main reasons for this are that Resemblance Nominalism is committed to modal realism, while our intuitions are actualist, and that his view does not follow our intuitions to the place where the having of a property is an intrinsic matter. This, I think, is correct - at least to the extent to which any intuitions concerning such matters can be relevant. But the bundle theory with tropes requires modal realism as well (see Manley ${ }^{16}$ ), and the existence of a substratum, or of multiply locatable

${ }_{16}$ Manley, D. 2002. Properties and Resemblance Classes. Noûs 36: 75-96. 
spatio-temporal entities such as immanent universals, certainly have a lot of incredulous stares of their own to face. Every one of the three theories at hand has its primitives and ontological commitments, and every single one of them has been, at some point, labelled as strongly counter-intuitive. I think that this is not surprising: a primitive or unexplained and unanalyzed claim is easily found counterintuitive, since by being primitive, it sounds mysterious (at least to the ones who don't find the primitive intuitively intelligible). Thus, generalizing perhaps just a little too much, primitives are often counter-intuitive in virtue of the simple fact that they are primitives. Consequently, and unsurprisingly, every theory bears its amount of counter-intuitiveness, and our three theories can hardly be distinguished on this ground. Perhaps some will think that some counter-intuitive claims are more counter-intuitive than others. One might think, like Rodriguez-Pereyra ${ }^{17}$ seems to think, that modal realism is the most counter-intuitive claim in the neighbourhood. But one might also think that an unknowable substratum is worse. Or one might find counter-intuitive the idea that there exists nothing more than properties, bundled together, and that objects are 'made out' of properties. I could tell you now which one of these claims I find the most counter-intuitive, and you could do the same, and it is very likely that we would not agree. What then ? How can we use intuitions as good criteria for evaluating metaphysical theories ? It seems we cannot. ${ }^{18}$

\section{Aesthetic Value and Theory Choice}

Does this mean that I recommend rejection of the use of intuitions in metaphysics, or of considerations about a theory's simplicity and parsimony (and similarly for other meta-theoretical criteria which I left aside here)? No, since, as mentioned above, they can be useful at least to some extent in some debates, but also because even if one of these criteria alone cannot do the job of telling us which theory is the best, the combination of several (or all) of the various meta-theoretical criteria could perhaps have the cumulative effect of selecting one candidate as being better than the others. But what would it mean to 'cumulate the effect' of these criteria? If the effect of one is such that it does not allow to give clear preference to one candidate, how can the effect of two, three or more such criteria 'become' decisive? Where exactly would the decision-making power come from?

This is where the view (i) that philosophical theories posses aesthetic properties such as "being elegant" or "being beautiful" which are partly grounded in the nonaesthetic meta-theoretical criteria such as those we have seen above, and (ii) that the attribution of these aesthetic properties plays a crucial role in selecting one theory as being better than the others, becomes of great service. In short, the view at hand is that philosophical theories are beautiful and that contemplating their beauty is what drives us to prefer one to another.

\footnotetext{
17 Rodriguez-Pereyra, G. 2002. Resemblance Nominalism, A Solution to the Problem of Universals. Oxford, p. 202.

18 In Benovsky, J. From experience to metaphysics: on experience-based intuitions and their role in metaphysics, forthcoming in Noûs, I critically discuss in detail the nature and the role of intuitions in metaphysics.
} 
The beauty of a sunset is grounded in its non-aesthetic properties such as having this or the other chromatic properties, and/or this or the other pattern of clouds, and so on. The beauty of philosophical theories is grounded in their non-aesthetic features such as those put forward by the various meta-theoretical criteria (internal consistency, explanatory power, capacity of being included in a wider network of human knowledge, compatibility with one's intuitions, and of course the various kinds of simplicity and parsimony). Thus, the claim that selection of the best theory is done in virtue of its aesthetic properties does not constitute an additional metatheoretical criterion on a par with the others, rather it makes this new criterion to be the cumulative effect of some or all of the non-aesthetic meta-theoretical features of a theory. It does not amount to the abandonment of all these meta-theoretical criteria, on the contrary, it makes sense of the way they function in the process of evaluation and selection of a candidate as being the best.

One way to see in what sense the claim that aesthetic properties of theories $d o$ allow us to make a choice, combined with the claim that the 'first-order' criteria enter into the grounding basis for the 'second-order' aesthetic properties of competing theories is to ask: if, first, we are all able to attribute properties like 'exhibiting such and such a kind of simplicity' and similar to our theories, and, second, we all have the same 'first-order' data (that is, we all know all the pro and con arguments there are for each theory, we know how they stand with respect to all of the meta-theoretical criteria mentioned above, etc.), and, third, we all work in a rational way - why is it that we don't all end up defending the same view?

Put this way, the question might seem somewhat naïve, but I believe it is genuine. The answer we can then give, keeping in mind all of the considerations we have taken into account in the preceding sections, is simple enough: some of us are more receptive to the beauty of desert landscapes, while others prefer the varied beauty of 'urban landscapes', such as, the crowded centres of skyscraperfilled big cities. Some feel attracted by Bauhaus simplicity, while others by Baroque complexity. Some of us feel aesthetically stimulated by simplicity of structure, yet others are more inclined towards simplicity and parsimony with respect to basic axioms of a theory. Some of us are struck by the elegance of a view that shows great explanatory power, while others feel more attracted towards a theory that preserves one's pre-theoretical intuitions. Since we therefore evidently do not all share the same taste for what is beautiful and what are supposed to be the relevant non-aesthetic features (especially, their weighting) in which the beautiful is grounded, it is only to be expected that we will not agree about which theory is the best candidate to choose. So, the claim that theories are to be evaluated according to their aesthetic properties does not help us in finding an agreement when selecting one candidate as the winner in the game, but is does help us in seeing why there is no such agreement. It helps us to see that there are different equally good theories available, and that there is no meta-theoretical criterion such that it would clearly have one particular theory defeat all others. Furthermore, it makes us realise that, individually, we are still justified in selecting one theory as the most preferable according to its aesthetic properties, which in turn depend both on its non-aesthetic properties, on the context of their creation, and on our personal taste, whose role it is to determine which of the non- 
aesthetic features (according to different weightings we might also importantly apply) are to give rise to the alleged beauty of the theory as a whole.

In a nutshell, here is then how the whole evaluative process of theories might be understood. First, the evaluator carefully examines a theory's theoretical virtues, such as, simplicity, parsimony, compatibility with intuitions, etc. in order to see which ones the theory possesses and to what degree. To this end, the evaluator must be a trained and competent philosopher. Evaluations of this kind are sometimes an objective matter, a matter on which different philosophers can agree, at least to some extent. For instance, it will usually not be very difficult to agree that nominalism fares better with respect to qualitative parsimony than the theory of Platonic universals. But of course, not all such evaluations are as easily decided: for instance, it is very much debated whether endurantism or perdurantism is better with respect to being compatible with our intuitions about personal identity. Thus, in many cases, these "first-order" evaluations are not something philosophers can easily agree on, including their status of being 'objective'. Indeed, already at this first stage, the evaluator will appeal to her personal preference, which is a kind of "philosophical taste", for such-and-such a way of seeing things.

Then we see the second stage, where one philosopher considers several competing theories that she has finished evaluating (that is, she has gone through the first stage on her own and has arrived at a firm opinion, for example, in that she believes that endurantism accommodates our intuitions about personal identity better than perdurantism). At this second stage, she has to choose, say, between endurantism and perdurantism. Suppose she thinks that endurantism is better with respect to our common sense intuitions and, in addition, is a more complex and intricate view, while perdurantism is a more revisionary, bolder, and structurally simpler view (as part of a more comprehensive assessment, she would voice an opinion on all the evaluative criteria mentioned above, of course). Her philosophical taste will here again play a role and tell her to go for one view rather than another, based on her aesthetic preference, say, for simplicity rather than complexity (and so, say, for perdurantism rather than endurantism). It is clear, then, that the evaluator's taste plays a role from the beginning to the very end of the evaluative process.

\section{Aesthetic Value, Truth, and Metaphysics}

Embracing the claim that aesthetic features of philosophical theories are good guides when it comes to theory evaluation and theory choice, has a consequence that might not be of everybody's meta-philosophical taste: a certain kind of anti-realism, at least when it comes to metaphysical theories, on which I focused in the discussion above. The worry can be simply put thus: even if we agree that theories possess aesthetic properties such as "being beautiful", why should beauty of a theory be a good criterion for its evaluation, since there seems to be no good reason to think that 
beauty is truth-conducive ${ }^{19}$ ? Indeed, if we aim at metaphysical truth, why should we think that beauty will lead us there ? A view which would claim that beauty is truth-conducive, could still provide an explanation of why different philosophers hold different views in a sense relevant to our discussion, but with the important difference that the claim here would be that only one of us is right - only one philosopher's choice leads to an adequate description of the way the world is. If beauty is truth-conducive then only one philosopher's aesthetic evaluations will guide her to metaphysical truth, the others being, more or less, mislead. This is actually not completely implausible since, remember, aesthetic properties of metaphysical theories are grounded in their non-aesthetic features, and the claim would here then mean that the good philosopher is the one who has a good taste with respect to those features and who is sensitive to the theories' beauty in the most relevant way, very much like a good art critic is capable of providing the best evaluations of some pieces of artworks by having her sensibility more finely tuned than her fellow colleagues.

To my mind, though, the view that beauty is truth-conducive is under-motivated. Naively asked : are we here invited to think that "the world is beautiful" in some sort of objective way and that beautiful theories are more likely to be true - that they represent the world correctly ? Why suppose that the world is such ?

It seems then a better strategy, in order to face the worry above, to accept that beauty is not truth-conducive, but claim that it still is the best guide when it comes to theory-choice. Behind this strategy lies a general view of philosophy in general and metaphysics in particular as being an enterprise whose task is to analyze, organize and systematize our concepts such as the concept of a material object or the concept of a property, in order to provide a better understanding of them and to show how they are able to explain some phenomena we encounter (such as attribute agreement, change over time, ...) and to explore how these concepts are related to one another. A different way to put this is to insist that metaphysics does not say how the world is, it says what our concepts are like. (I want to stress that this claim is to be distinguished from the claim that metaphysics is conceptual analysis - a

\footnotetext{
19 Compare to Todd, C. 2008. Unmasking the Truth beneath the Beauty: Why the Supposed Aesthetic Judgements Made in Science May Not Be Aesthetic At All. International Studies in the Philosophy of Science 22, and McAllister, J. 1999. Beauty \& Revolution in Science. Cornell University Press, who are both concerned with physics and not metaphysics. Todd claims that aesthetic properties (of physical theories) do not help in the matter of empirical adequacy of the theory. McAllister offers a less radical position, one which fundamentally leaves open the question of whether aesthetic properties of physical theories are truth-conducive or not: "[...] it may still be that there are aesthetic criteria that are reliable indicators of the empirical adequacy of theories. [...] There may or may not be correlations between theories' having particular aesthetic properties and their having high degrees of empirical adequacy. If there are not such correlations, then no method of forming criteria for theory evaluation will identify any. But if some correlations exist, then inductive projection will be at least as likely to discover them as any alternative procedure for formulating criteria. This argument leaves open the question of whether aesthetic properties of theories that are correlated with high degree of empirical adequacy actually exist." (pp. 100-101) McAllister concludes his discussion by saying "I see little evidence that aesthetic properties correlated with high degrees of empirical adequacy in theories have yet been identified in any branch of science. If they had, the empirical benefit of choosing theories on particular aesthetic criteria would be far more obvious than it currently is." (p. 102)
} 
claim I do not (want to, need to) endorse. ${ }^{20}$ But I do hold a broadly Kantian view ${ }^{21}$ ). This picture of the way metaphysics works goes then as follows :

(i) we start with the concepts we have (like the concept of an ordinary material object), where such concepts can, in principle, both be given to us a priori or from experience

(ii) we want to better understand the concepts we have, and understand the connections and relations between them

(iii) to this end, we may introduce new theoretical concepts (like a substratum, or a relation of compresence)

(iv) this gives rise to a theory that is an organization and systematization of our concepts including the new theoretical ones (note that while doing this it may so happen that we are forced to revise or abandon some of the concepts we started with)

If this is correct, that is, if metaphysical theories are about our concepts rather than about the world, then when we evaluate metaphysical theories, we should not ask "is this theory correctly and adequately describing the world ?" - rather we should ask "is this theory a good/bad analysis and systematization of our concepts ?" Thus, when facing a situation such as the case we have seen above of the Theory of Universals, Trope Theory, and Nominalism, we can, and we should, recognize that there are three equally good theories. Indeed, all three theories have their pro and con arguments, all three can be evaluated in terms of their meta-theoretical nonaesthetic features, but still we are in a position where there is no objective consensus and no objective way to select one of them as being a clear winner of the game. Another way to put this is to say that metaphysical theories are theoretical and conceptual models of reality - where alternative, equally good, models can be available. $^{22}$

\footnotetext{
${ }^{20}$ There are two central claims typically endorsed by friends of conceptual analysis which I reject: first, the claim that metaphysics is a purely armchair a priori affair, and second, the weight defenders of conceptual analysis put on the role our intuitions play in metaphysics (see Benovsky, J. From experience to metaphysics: on experience-based intuitions and their role in metaphysics, forthcoming in Noûs). (On conceptual analysis and the role of intuitions in philosophy see, inter alia, Bealer, G. 1987. The Philosophical Limits of Scientific Essentialism. Philosophical Perspectives 1:289-365; Chalmers, D. 1996. The Conscious Mind: In Search of a Fundamental Theory. Oxford University Press; Jackson, F. 1994. Armchair Metaphysics. In Jackson, F. 1998. Mind, Method, and Conditionals: Selected Essays. London: Routledge, pp. 154-176; Jackson, F. 1998. From Metaphysics to Ethics, Oxford: Oxford University Press.)

21 In (i) below and in what follows in this section, I hold a broadly Kantian view, the relevant point of which being here, roughly, that our concepts are not guaranteed to give us the world. The general idea being that, on the one hand, there is the world, and on the other hand, there is us, with our contingent and limited perceptual systems and cognitive faculties - thus, we are only ever given how the world appears to us (both conceptually and in perception), but not how the world is independently of us. See Benovsky, J. From experience to metaphysics: on experience-based intuitions and their role in metaphysics, forthcoming in Nô̂s, for a detailed discussion.

22 Compare to Paul, L. A. 2012. Metaphysics as Modeling: The Handmaiden's Tale. Philosophical Studies, who seems to hold a similar view concerning this particular point, but restricts her claim only to a sub-class of metaphysical theories: "Metaphysical theories exploring parts of the world that are in principle accessible to scientists should be taken as describing toy models of the empirical facts, where such models represent ways the world might be, given the information we have to date. These models can
} 
But wait, one of the theories says that there are substrata, while the other two deny this claim - so surely, only one of them can be right ! No, because what we do when we say that there is a substratum is not to say what there is in the world, rather, we introduce a new theoretical concept that allows to systematize, organize, and understand the concepts of material object and property in such a way that we have a satisfactory answer to the questions we started with. But, as the dialectical situation of the example of our three theories shows, this answer can also be given within a different framework of concepts that do not include a substratum but rather, say, a concept of resemblance or a concept of compresence. Thus, endorsing the view that metaphysics is about our concepts allows one to abandon the fantasy that there is one true theory about the world to be found, and gives one the possibility of acknowledging that there are several equally good (even if conflicting) theories around.

Bearing such a view in mind, we can now lighten our burden concerning the worry that there is no good reason why aesthetic properties of theories should be truth-conducive. Indeed, it can be acknowledged that beauty is not truth-conducive in the sense of 'finding out the theory which adequately describes the world', but this does not create a problem since if metaphysics is not about describing the world, but about analyzing and systematizing our concepts, such as the concept of an object or a concept of a property, the need for any link between beauty and empirical adequacy or adequacy of a description does not arise. We can thus have a good answer to the question why different equally well informed and rational philosophers diverge in their choice of the best theory, while avoiding the worry from truth-conduciveness by simply denying the need for it.

In fact, the failure of the traditional meta-theoretical criteria to adjudicate between metaphysical theories suggests such an anti-realist view of metaphysics. As an argument for these or other forms of anti-realism we can then point out that disagreement among equally rational and well-informed practitioners of metaphysics is best explained by the suggestion that aesthetic considerations are driving theory choice, and the fact that aesthetic considerations are driving theory choice at least seems to suggest that metaphysics isn't aiming at truth about the world, in the sense of providing an adequate description of it. ${ }^{23}$

\footnotetext{
Footnote 22 continued

be compared in terms of elegance, simplicity, empirical adequacy (to the extent that empirical facts are known) and consistency with contemporary science, but should not be adopted as true [...] Science and empirical discoveries will ultimately determine which, if any, of the toy models provided by metaphysicians should be given the status of a true theory of the world."

23 I am very grateful to Fabrice Correia, Damiano Costa, Coralie Dorsaz, Fabian Dorsch, Michael Esfeld, Akiko Frischut, Amanda Garcia, Lynda Gaudemard, Rob Hopkins, Thomas Jacobi, Kathrin Koslicki, Baptiste Le Bihan, Jessica Leech, Clare Mac Cumhaill, Olivier Massin, Kevin Mulligan, L. A. Paul, Alain Pé-Curto, Gonzalo Rodriguez-Pereyra, Martine Nida-Ruemelin, Gianfranco Soldati, and Cain Todd for comments and suggestions that significantly helped me to improve parts of this paper.
} 